\author{
Andrew Schiff', Brenna L Brady ${ }^{2 *}$, \\ Sudip K Ghosh ${ }^{1}$, Sanjoy Roy ${ }^{2}$, Charles \\ Ruetsch $^{2}$ and Elliott Fegelman ${ }^{1}$ \\ ${ }^{1} J o h n s o n$ \& Johnson, Cincinnati, Ohio, USA \\ ${ }^{2}$ Health Analytics, LLC, Columbia \\ Dates: Received: 21 September, 2016; Accepted: \\ 02 November, 2016; Published: 03 November, 2016 \\ *Corresponding author: Brenna L Brady, PhD, \\ Health Analytics, LLC, Columbia 9200 Rumsey \\ Rd Suite 215 Columbia, 21045 MD, E-mail: \\ bbrady@healthanalytic.com

\section{Review Article \\ Estimated Rate of Post-Operative Anastomotic Leak Following Colorectal Resection Surgery: A Systematic Review}

www.peertechz.com

ISSN: 2455-2968

Keywords: Colorectal resection; Anastomotic leak; Post-operative; Patient factors

\section{Abstract}

Purpose: Anastomotic leak following colorectal resection surgery is associated with short and long-term negative patient outcomes, prolonged hospitalization, and increased healthcare costs. Various patient related and surgical factors are known to contribute to the development of postoperative anastomotic leaks. This study systematically reviewed the literature to assess the incidence of post-operative leak and identify patient factors associated with the development of leaks.

Methods: Articles published from 1/1/2003 - 8/8/2015 reporting on post-operative anastomotic leak following colorectal resection surgery were identified in the Medline and Embase databases. The rate of post-operative leak, as well as patient and surgical characteristics, were extracted.

Results: Forty-three articles met study inclusion criteria. Within the 14,102 cases, 867 patients experienced anastomotic leak, yielding an average leak rate of $6.1 \%$. Patients were primarily male $(57.0 \%)$ and had a mean age of 60.2 years. The majority of patients received a stapled anastomosis (70.9\%), and most resection surgeries were performed for a diagnosis of cancer $(80.7 \%)$. Comparison of patient characteristics with and without a post-operative leak revealed male gender, diabetes, open surgical procedures, and sutured anastomoses to be risk factors of anastomotic leak. Patients with anastomotic leak had a longer length of stay in the hospital and higher mortality rate than patients without a leak

Conclusions: Anastomotic leak remains a major concern in colorectal resection surgery and occurs in approximately $6.1 \%$ of cases. Both patient and surgical factors are associated with the development of post-operative anastomotic leak, which is linked to negative patient outcomes and increased mortality.

\section{Background}

Colorectal resection surgery is performed to remove diseased or malignant tissue in patients with benign disease or cancer for whom less invasive treatment options have failed [1,2]. Although surgical techniques have evolved over time, significant complications within colorectal resection surgeries remain, most notably the development of post-operative anastomotic leak. At a high level, an anastomotic leak is defined as leakage of the luminal contents from a wound or drain site; leaks can mbe minor and resolve on their own, or severe and require surgical intervention or other medical procedures to resolve the leakage [3]. There are various levels or grades of anastomotic leakage which are defined based on severity, symptomology, location, and method of detection [3]. The development of post-operative anastomotic leak is one of the most concerning complications in colorectal resection surgery as it is associated with negative patient outcomes including increased risk of abscess or fistula development, greater incidence of infection or sepsis, prolonged hospital stays and a greater risk of post-operative mortality [2,4-7]. Patients who experience anastomotic leak following colorectal resection surgery are also at an increased risk of cancer recurrence, impaired function of pelvic organs, and a permanent stoma $[5,8]$.
Anastomotic leak is estimated to occur in $0.5 \%$ to $26 \%$ of cases, with low colorectal and coloanal anastomosis posing the greatest risk of leak $[2,4-6,9,10]$. Surgical factors including operative time, experience of the surgeon, hospital and surgeon case load, and incidence of intraoperative complications have also been shown to be related to the development of anastomotic leaks [2,10-12]. The impact of other factors including laparoscopic versus open surgical techniques, as well as the use of staples versus sutures in anastomoses, remain unclear $[2,5,6,10,13]$. Additionally, patient related factors including being a smoker, male gender, and increased numbers of comorbidities have also been shown to be associated with higher rates of anastomotic leak [2,10,12-17].

Patients who experience anastomotic leak not only exhibit worse outcomes than patients without a leak, but they also incur greater healthcare costs. Estimates indicate that patients with a leak incur healthcare costs approximately 2-3 fold higher than patients without a leak $[4,5]$. Elevated healthcare costs are partially due to increased length of stay in the hospital, which is approximately doubled for patients with an anastomotic leak, as well as an increased rate of hospital readmission [4,5]. Treatments for anastomotic leak which can range from antibiotics to reoperation for anastomosis repair or 
diversion also have the potential to dramatically increase the overall cost of care $[4,6]$.

Considering the impact that anastomotic leak has on patients undergoing colorectal resection surgery, a clear understanding of the rate of anastomotic leak, as well as predisposing factors, is needed. This study conducted a systematic review in the Medline and Embase databases to provide estimates of the incidence of anastomotic leak following colorectal resection surgery based on recently published peer reviewed literature. Focus was placed on the rate of anastomotic leak following colorectal resection surgery, as well as the operative and patient specific factors associated with the development of a postoperative anastomotic leak.

\section{Methods}

\section{Search methods and procedures}

A systematic search of the Medline and Embase databases was performed to identify articles reporting on the rate of post-operative anastomotic leak following colorectal resection surgery. The search terms and inclusion and exclusion criteria were developed by a panel of experts on the surgical treatment of gastroenterological diseases following a preliminary review of the peer-reviewed literature. References from articles that met study criteria were also reviewed to expand the search.

\section{Search terms}

The Medline and Embase databases were searched for articles published in English from January 1, 2003 to August 8, 2015 that reported on the incidence of post-operative leak following colorectal resection surgery. The search terms included the population being studied, intervention, and outcome of the review (Table 1).

\section{Types of studies}

Only full text articles were included in the review; conference abstracts, editorials, and letters to the editor were excluded. Article types in the review included randomized controlled trials (RCTs), prospective outcome studies, clinical trials, comparative studies, evaluations, and observational studies.

\section{Study participants}

Only articles with adult populations (age $\geq 18$ years) that reported the incidence of post-operative leak after anastomosis in colorectal surgery were included.

\section{Measures}

Study outcomes extracted included study sample size, type(s) of anastomosis (e.g. staple versus suture), and diagnosis leading to surgery, patient demographics, comorbidities, mortality rate, operative characteristics, and length of hospital stay. Post-operative leak rate was the only required outcome; all other outcomes were extracted where available.

\section{Screening and reviewing process}

All review processes were conducted by two independent reviewers; any discrepancies between the two reviewers were reconciled by a third reviewer. The search returned a total of 562 articles. The screening process was initiated with an abstract review; articles were included if they referenced the prevalence of postoperative leaks following colon resection surgery. A full text review was then conducted for those articles that passed the abstract review (54 articles); articles that did not report the rate of post-operative leaks following colorectal anastomosis were excluded. The screening and review phases, led to exclusion of 381 publications leaving 43 studies in the final review (Table 2).

Extracted fields included author, title, date, journal, year of publication, rate of post-operative leak, and study outcomes. Costs associated with anastomotic leak was not assessed in this study, as cost of care was not reported within the articles.

\section{Statistical analyses}

For each of the 34 studies included in the review that stated on the type of anastomosis used frequencies of anastomotic were reported by each type of anastomosis. Similarly the frequency of leaks by surgical type were reported for the 34 studies in which the relationship was described. Finally demographic and operative leak rates were reported for the leak versus no leak groups in the subset of 12 articles included in this sample; there were varying numbers of articles within this subset included based on the demographic or operative characteristics reported within. Statically significant differences in leakage rates were assessed by chi square tests of equality of proportions. Pairwise comparisons were examined where significant omnibus tests were achieved. Statistical analyses were conducted with SPSS (version 20, Chicao, IL), and a critical alpha level of 0.05 was set.

\section{Results}

\section{Sample demographics}

A total of 14,102 cases were represented within the 43 articles included in the review. Of the 43 articles studies 19 were conducted in Europe (44.2\%), 18 were from Asia (41.9\%), and six were from North America (13.9\%). Overall the sample was primarily male (57\%) and of middle age (60.2 years), reported in 38 and 35 articles respectively (Table 3). Within the 18 articles that reported BMI, the weighted

\begin{tabular}{|l|l|}
\hline \multicolumn{2}{|l|}{ Table 1: Search Terms and Filters. } \\
\hline Search Term & Definition \\
\hline Description & $\begin{array}{l}\text { colon, OR colonic, OR colorectal, OR rectal, OR rectum, } \\
\text { OR “lower anterior resection", OR “low anterior resection", } \\
\text { OR "LAR sigmoidectomy", OR “left hemicolectomy", OR } \\
\text { "total mesorectal excision", OR TME }\end{array}$ \\
\hline Colon & postoperative, OR "post-operative", OR "post discharge" \\
\hline Post-operative & $\begin{array}{l}\text { complication, OR abscess, OR leak, OR anastomosis, } \\
\text { OR infection, OR ileus, OR bleeding, OR transfusion, OR } \\
\text { cost, OR sepsis, OR ureter, OR hernia, OR obstruction, } \\
\text { OR recurrence, OR TPN, OR "total parenteral nutrition" }\end{array}$ \\
\hline Leak & $1 / 1 / 2003$ - 8/8/2015 \\
\hline Filters & English \\
\hline Date Range & 18 - 64 \\
\hline Language & \\
\hline Age &
\end{tabular}


Table 2: Included Articles

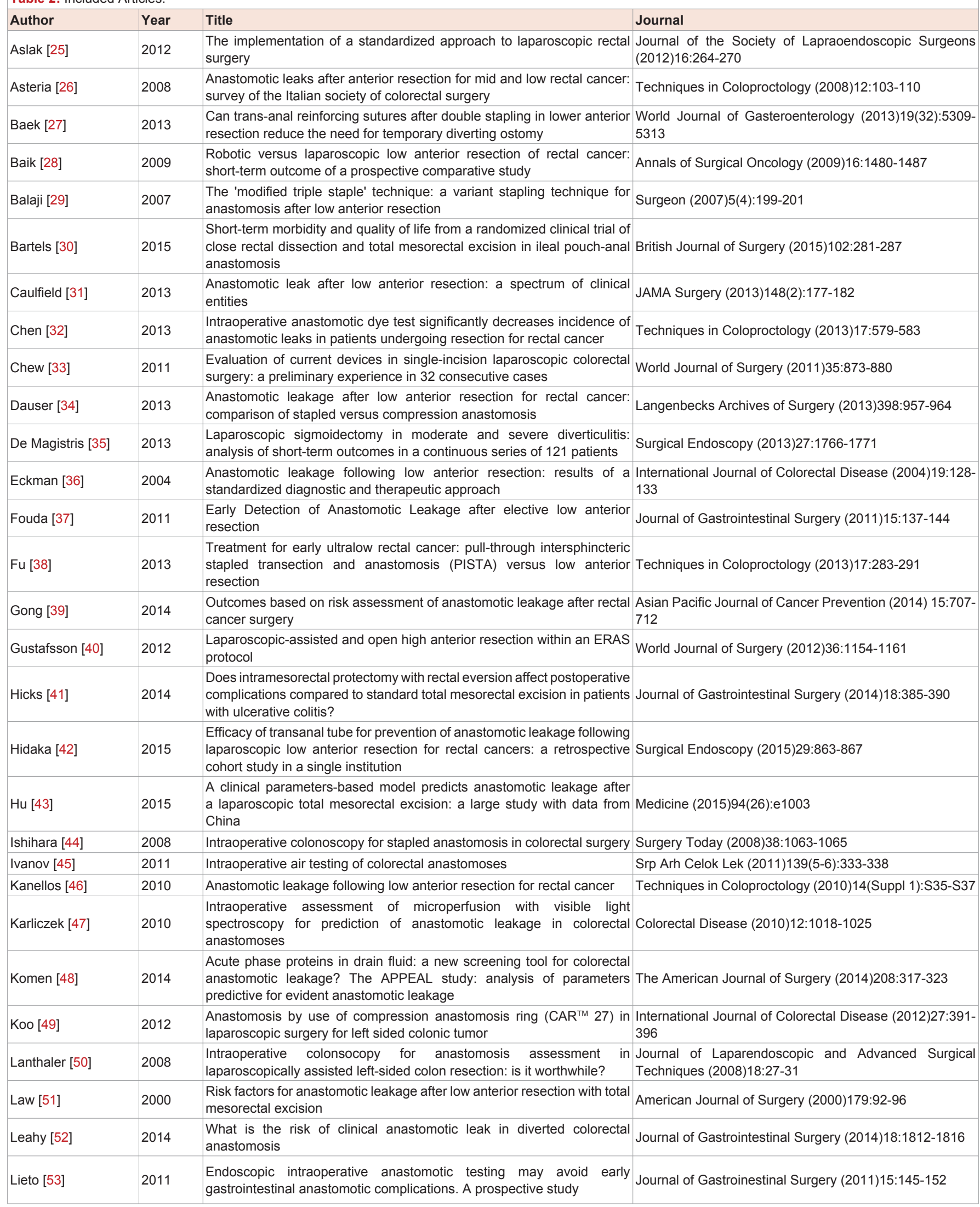




\begin{tabular}{|c|c|c|c|}
\hline Matthiessen [54] & 2007 & $\begin{array}{l}\text { Defunctioning stoma reduces symptomatic anastomotic leakage after } \\
\text { low anterior resection of the rectum for cancer }\end{array}$ & Annals of Surgery (2007)246:207-214 \\
\hline Morse [55] & 2013 & $\begin{array}{l}\text { Determination of independent predictive factors for anastomotic leak: } \\
\text { analysis of } 682 \text { intestinal anastomoses }\end{array}$ & The American Journal of Surgery (2013)206:950-956 \\
\hline Park [56] & 2013 & $\begin{array}{l}\text { Robotic-assisted transabdominal intersphincteric resection: a technique } \\
\text { involving a completely abdominal approach and coloanal anastomosis }\end{array}$ & $\begin{array}{l}\text { Surgical Laparoscopy, Endoscopy, and Percutaneous } \\
\text { Techniques (2013)23(1):e5-e10 }\end{array}$ \\
\hline Placer [57] & 2014 & $\begin{array}{l}\text { Preventing complications in colorectal anastomosis: results of a } \\
\text { randomized controlled trial using bioabsorbable staple line reinforcement } \\
\text { for circular stapler }\end{array}$ & $\begin{array}{l}\text { Diseases of the Colon and Rectum (2014)57(10):1195- } \\
1201\end{array}$ \\
\hline Ricciardi [58] & 2009 & Anastomotic leak testing after colon resection: what are the data? & Archives of Surgery (2009)144(5):407-411 \\
\hline Schmidt [59] & 2003 & $\begin{array}{l}\text { Anastomotic leakage after low rectal stapler anastomosis: significance of } \\
\text { intraoperative anastomotic testing }\end{array}$ & European Journal of Surgical Oncology (2003)29:239-243 \\
\hline Seo [60] & 2013 & $\begin{array}{l}\text { Characteristics and risk factors associated with permanent stomas after } \\
\text { sphincter-saving resection for rectal cancer }\end{array}$ & World Journal of Surgery (2013)37:2490-2496 \\
\hline Shamiyeh [61] & 2012 & $\begin{array}{l}\text { Intraoperative endoscopy for the assessment of circular-stapled } \\
\text { anastomosis in laparoscopic colon surgery }\end{array}$ & $\begin{array}{l}\text { Surgical Laparoscopy, Endoscopy, and Percutaneous } \\
\text { Techniques (2012)22(1):65-67 }\end{array}$ \\
\hline Shiomi [62] & 2011 & $\begin{array}{l}\text { Diverting stoma in rectal cancer surgery. A retrospective study of } 329 \\
\text { patients from Japanese cancer centers }\end{array}$ & $\begin{array}{l}\text { International Journal of Colorectal Disease (2011)26:79- } \\
87\end{array}$ \\
\hline Shrikhande [63] & 2013 & $\begin{array}{l}\text { Perioperative outcomes after ultra low anterior resection in the era of } \\
\text { neoadjuvant chemoradiotherapy }\end{array}$ & Indian Journal of Gastroenterology (2013)32(2):90-97 \\
\hline Smith [64] & 2007 & $\begin{array}{l}\text { The efficacy of intraoperative methylene blue enemas to assess the } \\
\text { integrity of a colonic anastomosis }\end{array}$ & BMC Surgery (2007)7:15 \\
\hline Ulrich [65] & 2008 & $\begin{array}{l}\text { Early results from a randomized clinical trial of colon } \mathrm{J} \text { pouch versus } \\
\text { transverse coloplasty pouch after low anterior resection for rectal cancer }\end{array}$ & British Journal of Surgery (2008)95:1257-1263 \\
\hline Wang [66] & 2010 & $\begin{array}{l}\text { Selective laparoscopic lateral dissection of regional micrometastasis in } \\
\text { rectal carcinoma - ten years single center experience }\end{array}$ & Minimally Invasive Therapy (2010)19:345-349 \\
\hline Xiao [67] & 2011 & $\begin{array}{l}\text { Can transanal tube placement after anterior resection for rectal } \\
\text { carcinoma reduce anastomotic leakage rate? A single-institution } \\
\text { prospective randomized study }\end{array}$ & World Journal of Surgery (2011)35:1367-1377 \\
\hline
\end{tabular}

mean was 23.4, indicating a normal weight for the population (Table $3)$. The diagnosis leading to colorectal resection surgery was reported in 41 articles; the most common diagnosis was cancer, in $80.7 \%$ of cases $(11,379)$. Other diagnoses leading to colorectal resection surgery included inflammatory bowel disease (3.2\%), diverticulitis $(3.5 \%)$, and other (5.2\%), which included familial adenomatous, polyposis, polyps, benign tumor, radiation enteritis, stenosis, rectal prolapse, injury, angiodysplasia, reversal of previous surgical procedures, adenoma, ischemic bowel, perforation, and colonic obstruction (Table 3). Presence of a diabetes diagnosis was reported in 11 articles and $12.2 \%$ of the sample had diabetes (Table 3). Within the 9 articles that reported smoking status, $35.5 \%$ of the sample was found to be a current smoker or have previously smoked (Table 3).

\section{Operative characteristics}

Where available operative characteristics including type of anastomosis (staple, suture, or other), surgery type (laparoscopic or open), operative time, length of hospital stay, distance of anastomosis to anal verge, and 30 day mortality were extracted from studies.

The type of anastomosis was reported in 39 articles which included 10,885 cases. Stapled anastomosis was used in the majority of cases (70.9\%), followed by sutured anastomosis (4.5\%), and other (1.8\%) which included compression rings or missing data. The type of anastomosis was not stated in remaining 3,217 cases across 4 articles (Table 4). Surgery type was reported in a total of 24 articles. Laparoscopic surgery was employed in 4,840 cases (34.3\%) and open surgery was used in 2,447 cases (17.4\%); the type of surgery was not stated in the remaining 6,815 cases (Table 5).

The weighted mean operative time was 198.6 minutes within the 15 articles that reported duration of surgery. The location of the anastomosis in relation to the anal verge was reported in 16 studies and a mean distance of $6.7 \mathrm{~cm}$ was identified within the 4,850 cases. Patients were hospitalized for an average of 14.2 days following surgery ( 16 articles), and a 30 day mortality rate of $1.0 \%$ was identified within the sample ( $\mathrm{n}=6$ articles).

\section{Leak rate}

All 43 articles reported the rate of post-operative leaks. A total of 167 leaks were identified within 14,102 cases, yielding a total leak rate of $6.1 \%$ (Table 4 ). Across the individual studies the rate of leaks ranged from $0.5 \%$ to $19.2 \%$.

The leak rate by type of anastomosis was also examined within a subset of 34 articles (9,934 cases) in which both outcomes were reported. Within this subset a total of 579 post-operative leaks were identified, resulting in a leak rate of $5.8 \%$, similar to the overall sample of articles. Staple anastomosis was most common with 9,151 cases; within this group there were 516 leaks producing a leak rate of $5.6 \%$. A total of 534 cases had a suture anastomosis, and 48 of these patients had a post-operative leak (9.0\%). The 'other' category was comprised of anastomoses that used a compression ring or had missing data regarding closure. Within these 249 cases, a total of 15 leaks were identified post-operatively, yielding a leak rate of $6.0 \%$ (Table 4). Chi square tests revealed the rate of leaks in patients with a stapled anastomosis to be significantly lower compared to patients with a sutured anastomosis $(\mathrm{p}=0.001)$.

Similarly the rate of leaks by surgical type were also examined. The rate of leaks within the 4,430 cases who received laparoscopic surgery was $4.0 \%$ (total of 179 leaks). The leak rate in the laparoscopic sample 
was significantly lower than the post-operative leak rate of $6.3 \%$ (total 82 leaks) identified in the 1,306 open surgery cases ( $p=0.001)$.

\section{Leak group analysis}

Within the full sample of 43 articles a total of 12 articles were identified that presented patient demographic and surgical characteristics based on post-operative anastomotic leak group (leak versus no leak). Study outcomes were examined using the 4,856 cases within these articles to examine demographic and surgical characteristics associated with anastomotic leak.

The subset of patients in the leak group analysis was similar to the overall study sample. The majority of patients were male (54.6\%), and the mean age of the subset was 61.3 years. The subset had a mean BMI of 22.0 , and $39.4 \%$ and $13.0 \%$ had a history of smoking or diabetes respectively. The leak group had a higher percentage of males $(68.2 \%$ v $54.8 \%)$, smokers ( $46.3 \%$ v. $38.8 \%)$, and diabetics ( $23.4 \%$ v. $12.4 \%)$ compared to the no leak group (Table 6).

Operative characteristics of the leak group analysis subset were largely similar to the overall study sample. Anastomosis type followed the same trend with stapled anastomosis most commonly used $(92.3 \%)$, followed by sutured anastomosis (6.6\%), and other (1.0\%). Laparoscopic surgery was more prevalent in the leak group subset (74\% of procedures), as one of the three manuscripts that reported on surgical type only performed laparoscopic procedures. The length of stay was also similar at an average of 13.3 days following anastomosis surgery. Mortality within the leak group analysis subset was higher than the total sample at $2.3 \%(\mathrm{p}=0.03)$, as was operative time with an average of 235.9 minutes. The distance of the anastomosis to the anal verge was slightly lower in the leak group analysis subset with a mean of $4.9 \mathrm{~cm}$. The leak group had a significantly higher rate of sutured anastomoses (10.9\% v. $6.3 \%)$ and open surgeries (36\% v. $25.5 \%)$ compared to the no leak group $(\mathrm{p}<0.01)$. Operative time and distance to the anal verge was similar between leak groups (Table 6). There was

Table 3: Sample Demographics.

\begin{tabular}{|l|l|l|l|l|}
\hline & Articles & Total Sample & Subset Sample & Mean/\% \\
\hline Age (Years) & 35 & 10,676 & & 60.2 \\
\hline Gender & 38 & 11,510 & & \\
\hline Male & 38 & & 6,552 & $57.0 \%$ \\
\hline Female & 38 & & 4,958 & $43.0 \%$ \\
\hline BMI & 18 & 6,675 & & 23.4 \\
\hline Diagnosis & 43 & 14,102 & & \\
\hline Cancer & 38 & & 11,379 & $80.7 \%$ \\
\hline IBD & 6 & & 445 & $3.2 \%$ \\
\hline Diverticulitis & 7 & & 490 & $3.5 \%$ \\
\hline Other & 12 & & 740 & $5.2 \%$ \\
\hline Not Stated & 2 & & 1,048 & $7.4 \%$ \\
\hline Diabetes & 11 & 4,524 & 551 & $12.2 \%$ \\
\hline Smoker & 8 & 2,544 & 912 & $35.8 \%$ \\
\hline Demographics & $6 a s e d$ & & & \\
\hline
\end{tabular}

Demographics are based on the sample within the articles that reported a specific demographic. Means are the weighted mean from studies.
Table 4: Operative Details.

\begin{tabular}{|c|c|c|c|c|}
\hline & Articles & Total Sample & Subset Sample & Mean $/ \%$ \\
\hline Type of Anastomosis & 43 & 14,102 & & \\
\hline Stapled & 39 & & 10,000 & $70.9 \%$ \\
\hline Sutured & 15 & & 636 & $4.5 \%$ \\
\hline Other & 4 & & 249 & $1.8 \%$ \\
\hline Not stated & 4 & & 3,217 & $22.8 \%$ \\
\hline Surgical Type & 43 & 14,102 & & \\
\hline Open & 12 & & 2,447 & $17.4 \%$ \\
\hline Laparoscopic & 24 & & 4,840 & $34.3 \%$ \\
\hline Not stated & 19 & & 6,815 & $48.3 \%$ \\
\hline $\begin{array}{l}\text { Operative Time } \\
\text { (Minutes) }\end{array}$ & 15 & 2,575 & & 198.6 \\
\hline Length of Stay (Days) & 16 & 2,658 & & 14.2 \\
\hline $\begin{array}{l}\text { Distance to Anal Verge } \\
(\mathrm{cm})\end{array}$ & 16 & 4,850 & & 6.7 \\
\hline 30 Day Mortality & 16 & 3,267 & 35 & $1.00 \%$ \\
\hline
\end{tabular}

Operative details are based on the sample within the articles that reported a specific characteristic (e.g. type of anastomosis). Means are the weighted mean from studies.

\begin{tabular}{|l|l|l|l|l|}
\hline \multicolumn{5}{|l}{ Table 5: Anastomotic Leak Rates. } \\
\hline & Articles & Total Sample & Leaks & Leak Rate \\
\hline Post-operative Leaks & 43 & 14,102 & 867 & $6.1 \%$ \\
\hline By Anastomosis Type & 34 & 9,934 & 579 & $5.8 \%$ \\
\hline Stapled & 34 & 9,151 & 516 & $5.6 \%$ \\
\hline Sutured & 10 & 534 & 48 & $9.0 \%$ \\
\hline Other & 5 & 249 & 15 & $6.0 \%$ \\
\hline By Surgical Type & 18 & 5,736 & 261 & $4.6 \%$ \\
\hline Open & 6 & 1,306 & 82 & $6.3 \%$ \\
\hline Laparoscopic & 16 & 4,430 & 179 & $4.0 \%$ \\
\hline
\end{tabular}

a notable increase in both the length of hospitalization (12.4 v. 20.9 days) and 30 day mortality ( $1.8 \%$ v. $6.2 \%)$ in the leak group compared to the no leak group.

Comparison of leak rates by patient and surgical characteristics revealed that males $(\mathrm{p}<0.0001)$, patients with diabetes $(\mathrm{p}<0.0001)$, patients who had an open surgery $(\mathrm{p}=0.001)$, and patients who received a sutured anastomosis $(\mathrm{p}=0.001)$ were significantly more likely to experience a post-operative anastomotic leak compared to females, non-diabetics, and stapled anastomoses respectively.

\section{Discussion}

This study used a systematic review of the Medline and Embase databases to estimate the rate of anastomotic leak following colorectal resection surgery in the recently published literature. A total of 43 articles, corresponding to 14,102 cases were included in the review; the majority of cases underwent colorectal resection for cancer $(80.7 \%)$. The study sample was primarily male and of middle age (60.2 years), consistent with the demographics of colorectal cancer patients [18]. A total of 867 patients experienced an anastomotic leak, 
Table 6: Characteristics by Leak Group.

\begin{tabular}{|c|c|c|c|c|}
\hline & Articles & Total & Subset Sample & Mean $/ \%$ \\
\hline \multicolumn{5}{|l|}{ Demographics } \\
\hline Gender & 12 & & & \\
\hline No Leak & & 4536 & & \\
\hline Male & & & 2438 & $54.8 \%$ \\
\hline Female & & & 2098 & $47.2 \%$ \\
\hline Leak & & 320 & & \\
\hline Male & & & 212 & $68.2 \%$ \\
\hline Female & & & 108 & $34.7 \%$ \\
\hline Age & 10 & & & \\
\hline No Leak & & 4024 & & 61.3 \\
\hline Leak & & 276 & & 61.1 \\
\hline BMI & 4 & & & \\
\hline No Leak & & 2312 & & 22 \\
\hline Leak & & 118 & & 23.1 \\
\hline Smoker & 6 & & & \\
\hline No Leak & & 1798 & 698 & $38.8 \%$ \\
\hline Leak & & 147 & 68 & $46.3 \%$ \\
\hline Diabetes & 6 & & & \\
\hline No Leak & & 3431 & 426 & $12.4 \%$ \\
\hline Leak & & 197 & 46 & $23.4 \%$ \\
\hline \multicolumn{5}{|l|}{$\begin{array}{l}\text { Operating } \\
\text { Characteristics }\end{array}$} \\
\hline Type of Anastomosis & 12 & & & \\
\hline No Leak & & 4536 & & \\
\hline Stapled & & & 4201 & $92.6 \%$ \\
\hline Sutured & & & 287 & $6.3 \%$ \\
\hline Other & & & 48 & $1.1 \%$ \\
\hline Leak & & 320 & & \\
\hline Stapled & & & 282 & $88.1 \%$ \\
\hline Sutured & & & 35 & $10.9 \%$ \\
\hline Other & & & 3 & $0.9 \%$ \\
\hline Surgical Type & 3 & & & \\
\hline No Leak & & 2974 & & \\
\hline Open & & & 759 & $25.5 \%$ \\
\hline Laparoscopic & & & 2215 & $74.5 \%$ \\
\hline Leak & & 136 & & \\
\hline Open & & & 49 & $36.0 \%$ \\
\hline Laparoscopic & & & 87 & $64.0 \%$ \\
\hline Operative Time & 3 & & & \\
\hline No Leak & & 407 & & 236.3 \\
\hline Leak & & 55 & & 233.3 \\
\hline Length of Stay & 3 & & & \\
\hline No Leak & & 335 & & 12.4 \\
\hline Leak & & 41 & & 20.9 \\
\hline $\begin{array}{l}\text { Distance to Anal } \\
\text { Verge }\end{array}$ & 4 & & & \\
\hline No Leak & & 796 & & 4.9 \\
\hline Leak & & 91 & & 4.7 \\
\hline 30 Day Mortality & 3 & & & \\
\hline No Leak & & 492 & 9 & $1.8 \%$ \\
\hline Leak & & 65 & 4 & $6.2 \%$ \\
\hline
\end{tabular}

yielding a study post-operative leak rate of $6.1 \%$, which corresponds with the rate of post-operative leaks reported in multiple prospective and retrospective studies $[4,10,19]$. Although the overall rate of leaks identified in this study is toward the lower end of published estimates of post-operative leak, the range of post-operative leaks across individual studies within this review $(0.5-19.2 \%)$ is consistent with that of the published literature $(0.5-26 \%)[4-6,9,10]$.

Examination of surgical factors, including anastomosis and surgery type, revealed that patients who received a sutured anastomosis or underwent open surgery were significantly more likely to experience a post-operative leak compared to stapled anastomoses or laparoscopic surgery respectively. The majority of anastomoses included in the study were stapled $(70.9 \%)$ indicating a preference for the use of staplers in colorectal resection surgeries. Our finding that leaks are more common with sutured anastomoses is a diversion from the literature, which generally reports no difference in leak rate based on anastomosis type [20-22]. Differences in the time period assessed in this review, size of the sample, surgical characteristics (e.g. location of the anastomosis), or study inclusion criteria could account for the differences identified here. Laparoscopic procedures were more common than open surgeries within the sample, although the procedure used was not stated for $48.3 \%$ of the sample. Our finding that laparoscopic surgery is associated with a lower rate of postoperative anastomotic leak is not unprecedented [10]. Laparoscopic procedures may cause reduced tissue trauma as compared to open procedures and is associated with faster surgical recovery; previous findings of equality between the procedures are likely related to the study sample including patient and surgeon related factors, as well as the learning curve associated with laparoscopic procedures, that influence the outcome of the surgery $[23,24]$.

In an attempt to assess patient and surgical related factors related to the development of post-operative anastomotic leak, the subset of articles that reported demographic and operative characteristics based on the presence or absence of post-operative anastomotic leak were assessed. This analysis included a total of 12 articles that accounted for a total of 4,856 cases ( $34.4 \%$ of the total sample). The most commonly reported patient characteristics were gender and age, although smoking status and diabetes diagnosis was also assessed within the subset of the sample where they were reported. Consistent with previous reports, there was a greater percentage of males in the leak group compared to the no leak group ( $54.8 \%$ v. $68.2 \%$ ), which lead to a significantly increased rate of post-operative anastomotic leaks in the male versus female population $(8.0 \%$ v. $4.9 \%, \mathrm{p}<0.001)$ $[5,10,13]$. Although some of the articles included in this review have reported older age to be associated with a greater risk of anastomotic leaks $[26,30]$, there was no difference between the mean age of patients with a leak and patients without a leak in this sample, consistent with other reports $[10,12]$. There was a trend towards a higher rate of anastomotic leaks in patients who smoked compared to those who did not $(8.9 \%$ v. $6.7 \%)$, but this comparison did not reach statistical significance in our sample. Conversely, patients with diabetes were found to have a significantly greater post-operative anastomotic leak rate compared to individuals without diabetes $(9.7 \%$ v. $4.8 \%$, $\mathrm{p}<0.001)$. 
Similar to the analysis of leak rate by anastomosis type within the larger study sample, we found a significantly higher rate of leaks in the sutured group compared to the stapled group $(10.9 \%$ v. $6.3 \%, p=0.001)$. The rate of 'other' types of anastomoses was similar between groups ( $1.1 \%$ in the no leak group v. $0.9 \%$ in the leak group), and resulted in a post-operative leak rate of $5.9 \%$ in the 'other' anastomosis group. We also identified differences in post-operative outcomes across leak groups. In concert with previous findings, the leak group within this subset had a longer duration of hospitalization (20.9 v. 12.4 days) and a higher rate of mortality $(6.2 \% \mathrm{v} .1 .8 \%, \mathrm{p}=0.03)$ compared to the no leak group, indicating worse outcomes within the group of patients who experienced a post-operative anastomotic leak $[4,7,13]$.

This study assessed the rate of intraoperative leaks and factors associated with leaks within a sample of articles identified through systematic review of the Medline database. A study leak rate of $6.1 \%$ was found within a sample of 14,102 colorectal resection surgeries. Factors associated with the development of post-operative anastomotic leak were explored, although differences in reporting methodology across studies limited sample sizes and conclusions. Overall the presence of an anastomotic leak was associated with an increased length of hospitalization and higher mortality rates. We were able to identify several surgical factors that were significantly associated with the development of post-operative anastomotic leak, including open versus laparoscopic procedures and use of sutures compared to staples for the anastomosis. We also found a significantly increased anastomotic leak rate within males and patients with a diagnosis of diabetes. Due to the notable impact of anastomotic leak on both patient outcomes and healthcare utilization and costs, further studies to better understand the prevalence of anastomotic leak and predisposing factors are needed.

\section{Conflict of Interest}

Ethicon funded this study. A.S., S.K.G, S.R., and E.F. are employees of Johnson \& Johnson hold stock. B.L.B and C.R. are employees of Health Analytics, who received support from Johnson \& Johnson to conduct this study.

\section{References}

1. Daher R, Barouki E, Chouillard E (2016) Laparoscopic treatment of complicated colonic diverticular disease: A review. World J Gastrointest Surg 8: 134-142.

2. Kirchhoff P, Clavien PA, Hahnloser D (2010) Complications in colorectal surgery: risk factors and preventive strategies. Patient Saf Surg 4: 5

3. Bruce J, Krukowski ZH, Al-Khairy G, Russell EM, Park KG (2001) Systematic review of the definition and measurement of anastomotic leak after gastrointestinal surgery. Br J Surg 88: 1157-1168.

4. Hammond J, Lim S, Wan Y, Gao X, Patkar A (2014) The burden of gastrointestinal anastomotic leaks: an evaluation of clinical and economic outcomes. J Gastrointest Surg 18: 1176-1185.

5. Kang CY, Halabi WJ, Chaudhry OO, Nguyen V, Pigazzi A, et al (2013). Risk factors for anastomotic leakage after anterior resection for rectal cancer. JAMA Surg 148: 65-71.

6. Murrell ZA, Stamos MJ (2006) Reoperation for anastomotic failure. Clin Colon Rectal Surg 19: 213-216.

7. Krarup PM, Nordholm-Carstensen A, Jorgensen LN, Harling H (2015) Association of Comorbidity with Anastomotic Leak, 30-day Mortality, and Length of Stay in Elective Surgery for Colonic Cancer: A Nationwide Cohort Study. Dis Colon Rectum 58: 668-676
8. Oines MN, Krarup PM, Jorgensen LN, Agren MS (2014) Pharmacological interventions for improved colonic anastomotic healing: a meta-analysis. World J Gastroenterol 20: 12637-12648.

9. Blumetti J, Abcarian H (2015) Management of low colorectal anastomotic leak: Preserving the anastomosis. World J Gastrointest Surg 7: 378-383.

10. Trencheva K, Morrissey KP, Wells M, Mancuso CA, Lee SW, et al. (2013) Identifying important predictors for anastomotic leak after colon and rectal resection: prospective study on 616 patients. Ann Surg 257: 108-113.

11. Harmon JW, Tang DG, Gordon TA, Bowman HM, Choti MA, et al. (1999) Hospital volume can serve as a surrogate for surgeon volume for achieving excellent outcomes in colorectal resection. Ann Surg 230: 404-411.

12. Suding P, Jensen E, Abramson MA, Itani K, Wilson SE (2008) Definitive risk factors for anastomotic leaks in elective open colorectal resection. Arch Surg 143: 907-911.

13. Daams F, Luyer M, Lange JF (2013) Colorectal anastomotic leakage: aspects of prevention, detection and treatment. World J Gastroenterol 19: 2293-2297.

14. Kim MJ, Shin R, Oh HK, Park JW, Jeong SY, et al. (2011) The impact of heavy smoking on anastomotic leakage and stricture after low anterior resection in rectal cancer patients. World J Surg 35: 2806-2810.

15. Richards CH, Campbell V, Ho C, Hayes J, Elliott T, et al. (2012) Smoking is a major risk factor for anastomotic leak in patients undergoing low anterior resection. Colorectal Dis14: 628-633.

16. Soeters PB, de Zoete JP, Dejong CH, Williams NS, Baeten CG (2002) Colorectal surgery and anastomotic leakage. Dig Surg 19: 150-155.

17. Sorensen LT, Jorgensen T, Kirkeby LT, Skovdal J, Vennits B, et al. (1999) Smoking and alcohol abuse are major risk factors for anastomotic leakage in colorectal surgery. Br J Surg 86: 927-931.

18. Society AC (2011) Colorectal Cancer Facts \& Figures: 2011-2013.

19. Kwon S, Morris A, Billingham R, Frankhouse J, Horvath K, et al. (2012) Routine leak testing in colorectal surgery in the Surgical Care and Outcomes Assessment Program. Arch Surg 147: 345-351.

20. Lustosa SA, Matos D, Atallah AN, Castro AA (2002) Stapled versus handsewn methods for colorectal anastomosis surgery: a systematic review of randomized controlled trials. Sao Paulo Med J 120: 132-136.

21. MacRae HM, McLeod RS (1998) Handsewn vs. stapled anastomoses in colon and rectal surgery: a meta-analysis. Dis Colon Rectum 41: 180-189.

22. Neutzling CB, Lustosa SA, Proenca IM, da Silva EM, Matos D (2012) Stapled versus handsewn methods for colorectal anastomosis surgery. Cochrane Database Syst Rev 2: CD003144.

23. Biondi A, Grosso G, Mistretta A, Marventano S, Toscano C, et al. (2013) Laparoscopic vs. open approach for colorectal cancer: evolution over time of minimal invasive surgery. BMC Surg 13: S12.

24. Braga M, Vignali A, Gianotti L, Zuliani W, Radaelli G, et al. (2002) Laparoscopic versus open colorectal surgery: a randomized trial on shortterm outcome. Ann Surg 236: 759-766.

25. Aslak KK, Bulut O (2012) The implementation of a standardized approach to laparoscopic rectal surgery. JSLS 16: 264-270.

26. Asteria CR, Gagliardi G, Pucciarelli S, Romano G, Infantino A, et al. (2008) Anastomotic leaks after anterior resection for mid and low rectal cancer: survey of the Italian Society of Colorectal Surgery. Tech Coloproctol 12: 103110.

27. Baek SJ, Kim J, Kwak J, Kim SH (2013) Can trans-anal reinforcing sutures after double stapling in lower anterior resection reduce the need for a temporary diverting ostomy? World J Gastroenterol 19: 5309-5313.

28. Baik SH, Kwon HY, Kim JS, Hur H, Sohn SK, et al. (2009) Robotic versus laparoscopic low anterior resection of rectal cancer: short-term outcome of a prospective comparative study. Ann Surg Oncol 16: 1480-1487.

29. Balaji NS, Macklin CP, Fawole S, Aster AS, Rao VS, et al. (2007) The 'modified triple staple' technique: a variant stapling technique for anastomosis after low anterior resection. Surgeon 5: 199-201.

30. Bartels SA, Gardenbroek TJ, Aarts M, Ponsioen CY, Tanis PJ, et al. (2015) Short-term morbidity and quality of life from a randomized clinical trial of close rectal dissection and total mesorectal excision in ileal pouch-anal anastomosis. Br J Surg 102: 281-287. 
31. Caulfield H, Hyman NH (2013) Anastomotic leak after low anterior resection: a spectrum of clinical entities. JAMA Surg 148: 177-182.

32. Chen CW, Chen MJ, Yeh YS, Tsai HL, Chang YT, et al. (2013) Intraoperative anastomotic dye test significantly decreases incidence of anastomotic leaks in patients undergoing resection for rectal cancer. Tech Coloproctol 17: 579583

33. Chew MH, Wong MT, Lim BY, Ng KH, Eu KW (2011) Evaluation of current devices in single-incision laparoscopic colorectal surgery: a preliminary experience in 32 consecutive cases. World J Surg 35: 873-880.

34. Dauser B, Braunschmid T, Ghaffari S, Riss S, Stift A, et al. (2013) Anastomotic leakage after low anterior resection for rectal cancer: comparison of stapled versus compression anastomosis. Langenbecks Arch Surg 398: 957-964.

35. De Magistris L, Azagra JS, Goergen M, De Blasi V, Arru L, et al. (2013) Laparoscopic sigmoidectomy in moderate and severe diverticulitis: analysis of short-term outcomes in a continuous series of 121 patients. Surg Endosc 27: 1766-1771.

36. Eckmann C, Kujath P, Schiedeck TH, Shekarriz H, Bruch HP (2004) Anastomotic leakage following low anterior resection: results of a standardized diagnostic and therapeutic approach. Int J Colorectal Dis 19: 128-133.

37. Fouda E, El Nakeeb A, Magdy A, Hammad EA, Othman G, et al. (2016) Early detection of anastomotic leakage after elective low anterior resection. Gastrointest Surg 15: 137-144.

38. Fu CG, Gao XH, Wang H, Yu ZQ, Zhang W, et al. (2013) Treatment for early ultralow rectal cancer: pull-through intersphincteric stapled transection and anastomosis (PISTA) versus low anterior resection. Tech Coloproctol 17 283-291.

39. Gong JP, Yang L, Huang XE, Sun BC, Zhou JN, et al. (2014) Outcomes based on risk assessment of anastomotic leakage after rectal cancer surgery. Asian Pac J Cancer Prev 15: 707-712.

40. Gustafsson UO, Tiefenthal M, Thorell A, Ljungqvist O, Nygrens J (2012) Laparoscopic-assisted and open high anterior resection within an ERAS protocol. World J Surg 36: 1154-1161.

41. Hicks CW, Hodin RA, Savitt L, Bordeianou L (2014) Does intramesorecta proctectomy with rectal eversion affect postoperative complications compared to standard total mesorectal excision in patients with ulcerative colitis? J Gastrointest Surg 18: 385-390.

42. Hidaka E, Ishida F, Mukai S, Nakahara K, Takayanagi D, et al. (2015) Efficacy of transanal tube for prevention of anastomotic leakage following laparoscopic low anterior resection for rectal cancers: a retrospective cohort study in a single institution. Surg Endosc 29: 863-867.

43. Hu X, Cheng Y (2015) A Clinical Parameters-Based Model Predicts Anastomotic Leakage After a Laparoscopic Total Mesorectal Excision: A Large Study With Data From China. Medicine (Baltimore) 94: e1003.

44. Ishihara S, Watanabe T, Nagawa H (2008) Intraoperative colonoscopy for stapled anastomosis in colorectal surgery. Surg Today 38: 1063-1065.

45. Ivanov D, Cvijanovic R, Gvozdenovic L (2011) Intraoperative air testing of colorectal anastomoses. Srp Arh Celok Lek 139: 333-338.

46. Kanellos D, Pramateftakis MG, Vrakas G, Demetriades H, Kanellos I, et al (2014) Anastomotic leakage following low anterior resection for rectal cancer. Tech Coloproctol 14: S35-37.

47. Karliczek A, Benaron DA, Baas PC, Zeebregts CJ, Wiggers T, et al. (2010) Intraoperative assessment of microperfusion with visible light spectroscopy for prediction of anastomotic leakage in colorectal anastomoses. Colorectal Dis 12: 1018-1025.

48. Komen N, Slieker J, Willemsen P, Mannaerts G, Pattyn P, et al. (2014) Acute phase proteins in drain fluid: a new screening tool for colorectal anastomotic leakage? The APPEAL study: analysis of parameters predictive for evident anastomotic leakage. Am J Surg 208: 317-323.

49. Koo EJ, Choi HJ, Woo JH, Park KJ, Roh YH, et al. (2012) Anastomosis by use of compression anastomosis ring (CAR 27) in laparoscopic surgery for left-sided colonic tumor. Int J Colorectal Dis 27: 391-396.
50. Lanthaler M, Biebl M, Mittermair R, Ofner D, Nehoda H (2008) Intraoperative colonoscopy for anastomosis assessment in laparoscopically assisted leftsided colon resection: is it worthwhile? J Laparoendosc Adv Surg Tech A 18: 27-31.

51. Law WI, Chu KW, Ho JW, Chan CW (2000) Risk factors for anastomotic leakage after low anterior resection with total mesorectal excision. Am J Surg 179: $92-96$

52. Leahy J, Schoetz D, Marcello P, Read T, Hall J, et al. (2014) What is the risk of clinical anastomotic leak in the diverted colorectal anastomosis? J Gastrointest Surg 18: 1812-1816.

53. Lieto E, Orditura M, Castellano P, Pinto M, Zamboli A, et al. (2011) Endoscopic intraoperative anastomotic testing may avoid early gastrointestinal anastomotic complications. A prospective study. J Gastrointest Surg 15: 145152 .

54. Matthiessen P, Hallbook O, Rutegard J, Simert G, Sjodahl R (2007) Defunctioning stoma reduces symptomatic anastomotic leakage after low anterior resection of the rectum for cancer: a randomized multicenter trial. Ann Surg 246: 207-214.

55. Morse BC, Simpson JP, Jones YR, Johnson BL, Knott BM, et al. (2013) Determination of independent predictive factors for anastomotic leak: analysis of 682 intestinal anastomoses. Am J Surg 206: 950-955.

56. Park SY, Choi GS, Park JS, Kim HJ, Choi WH, et al. (2013) Robotic-assisted transabdominal intersphincteric resection: a technique involving a completely abdominal approach and coloanal anastomosis. Surg Laparosc Endosc Percutan Tech 23: e5-10.

57. Placer C, Enriquez-Navascues JM, Elorza G, Timoteo A, Mugica JA, et al. (2014) Preventing complications in colorectal anastomosis: results of a randomized controlled trial using bioabsorbable staple line reinforcement for circular stapler. Dis Colon Rectum 57: 1195-1201.

58. Ricciardi R, Roberts PL, Marcello PW, Hall JF, Read TE, et al. (2009) Anastomotic leak testing after colorectal resection: what are the data? Arch Surg 144: 407-411.

59. Schmidt O, Merkel S, Hohenberger W (2003) Anastomotic leakage after low rectal stapler anastomosis: significance of intraoperative anastomotic testing. Eur J Surg Oncol 29: 239-243.

60. Seo SI, Yu CS, Kim GS, Lee JL, Yoon YS, et al. (2013) Characteristics and risk factors associated with permanent stomas after sphincter-saving resection for rectal cancer. World J Surg 37: 2490-2496.

61. Shamiyeh A, Szabo K, Ulf Wayand W, Zehetner J (2012) Intraoperative endoscopy for the assessment of circular-stapled anastomosis in laparoscopic colon surgery. Surg Laparosc Endosc Percutan Tech 22: 65-67.

62. Shiomi A, Ito M, Saito N, Ohue M, Hirai T, et al. (2011) Diverting stoma in rectal cancer surgery. A retrospective study of 329 patients from Japanese cancer centers. Int J Colorectal Dis 26: 79-87.

63. Shrikhande SV, Bodhankar YD, Suradkar K, Goel M, Shukla PJ (2013) Perioperative outcomes after ultra low anterior resection in the era of neoadjuvant chemoradiotherapy. Indian J Gastroenterol 32: 90-97.

64. Smith S, McGeehin W, Kozol RA, Giles D (2007) The efficacy of intraoperative methylene blue enemas to assess the integrity of a colonic anastomosis. BMC Surg 7: 15

65. Ulrich AB, Seiler CM, Z'Graggen K, Loffler T, Weitz J, et al. (2008) Early results from a randomized clinical trial of colon $J$ pouch versus transverse coloplasty pouch after low anterior resection for rectal cancer. Br J Surg 95 1257-1263

66. Wang C, Zhou ZG, Yu YY, Yang L, Wang ZQ, et al. (2010) Selective laparoscopic lateral dissection of regional micrometastasis in rectal carcinoma--ten years single center experience. Minim Invasive Ther Allied Technol 19: 345-349.

67. Xiao L, Zhang WB, Jiang PC, Bu XF, Yan Q, et al. (2011) Can transanal tube placement after anterior resection for rectal carcinoma reduce anastomotic leakage rate? A single-institution prospective randomized study. World $\mathrm{J}$ Surg 35: 1367-1377.

Copyright: (c) 2016 Schiff A, et al. This is an open-access article distributed under the terms of the Creative Commons Attribution License, which permits unrestricted use, distribution, and reproduction in any medium, provided the original author and source are credited. 